\title{
NORMAL STANDARDS FOR SINGLE BREATH TESTS OF VENTILATORY CAPACITY IN CHILDREN
}

\author{
BY \\ BRYAN GANDEVIA \\ From the Clinical Research Department, Royal Children's Hospital, Melbourne
}

(RECEIVED FOR PUBLICATION DECEMBER 21, 1959)

Tests of ventilatory capacity based on the recording of a maximum forced expiration after a full inspiration are becoming increasingly widely used. They are quicker to perform and require less cooperation and effort on the part of the subject than the conventional maximum breathing capacity estimation, and the results are more informative because three indices of ventilatory capacity, each of different significance, are derived from the recording of this simple manoeuvre. These indices are: (1) the forced vital capacity, (2) the volume of gas expired over a given time interval (usually the first second or half second), and (3) the percentage of the vital capacity (or forced vital capacity) expired within the same time period (that is, 2 as a percentage of 1). In this department the procedure has been found most appropriate in paediatric work; the children learn it readily and can repeat it frequently with, in my experience, greater consistency than the maximum breathing capacity test.

Adequate normal standards are available for the vital capacity (Turner and McLean, 1951; Jones, 1955), and this paper provides data relating to the percentage of the vital capacity expired in the first second and half second of a forced expiration.

\section{Definitions and Terminology}

The recording obtained when the subject, after a full inspiration, forcibly and completely exhales into a spirometer, the movement of which is recorded with a kymograph, is termed the forced expiratory spirogram (F.E.S.). The volumes of gas exhaled in the first half second and the first second of expiration are termed the forced expiratory volume at half a second (F.E.V.0.5) and one second (F.E.V.1.0) respectively. The total volume of gas expired is termed the forced vital capacity (F.V.C.). The qualification 'forced' is added to distinguish this measurement from the vital capacity (V.C.) estimated in the conventional manner, that is, when the expiration, in the earlier phases at least, is comparatively 'unforced'. The distinction is necessary because in certain pathological states the values for the vital capacity differ according to whether the expiration is forced or not; in emphysema, for example, 'air-trapping' leads to a forced vital capacity which is smaller than the vital capacity. The 'expired percentage' at 0.5 second or 1.0 second is the percentage of the V.C.* expired in the appropirate time interval and is abbreviated to F.E.V.0.5\% or $\mathrm{FEV}_{1.0} \%$; it is therefore equal to $\frac{\text { F.E.V. } 0.5}{\text { V.C. }}$ $\times 100$ or $\frac{\text { F.E.V. } 1 \cdot 0}{\text { V.C. }} \times 100$.

The terminology set out above is in accord with that adopted and recommended for general usage by the Thoracic Society of Great Britain (Gandevia and Hugh-Jones, 1957). It replaces or modifies a remarkable variety of different names employed by different workers in different countries for tests and their results which are essentially similar.

\section{Methods}

The spirometer used was of the type described by Bernstein and others (1952) to minimize various errors in the response of the bell to the sudden entry of gas. All connexions were of wide bore to reduce resistance to gas flow. The patient fitted a valveless anaesthetic mask, of adult or child size, with a one-inch outlet, to his face; a face mask has been found more convenient and less disturbing for the patient than the usual mouthpiece and noseclip. A Palmer kymograph was set to give a paper speed of $3.0 \mathrm{~cm}$. per second. No timing device was employed during the recordings but the speed of the kymograph was periodically checked against a mechanical time-marker. Tracings were not begun until the drum had moved approximately $10 \mathrm{~cm}$. One

* The F.V.C. is used by many workers in preference to the V.C. However, the latter is the more repeatable estimation and, in my view, the more fundamental characteristic. Numerically the difference is negligible except when there is significant 'air-trapping'. 
centimetre of travel of the bell was produced by the entry of $300 \mathrm{ml}$. of gas; this calibration was carefully checked by direct measurement of the internal diameters of the bell throughout its length.

After their height* (without shoes) had been measured the subjects were seated at a comfortable height in relation to the spirometer. The tests were explained and the fit of the face mask demonstrated and checked. The V.C. was then estimated in the conventional manner. Several recordings of forced expiration were made. The number of recordings of vital capacity and of forced expiration varied from subject to subject; four 'satisfactory' recordings of vital capacity and three of forced expiration were required, the mean value of these estimates being accepted. By 'satisfactory' is meant a recording free of artefacts and of mistakes on the part of the subject as judged by eye. Misleading tracings due to misunderstanding or obviously incomplete co-operation were discarded. In most instances 'satisfactory' therefore implies reasonable consistency. The statistical criticisms of this procedure are appreciated but it was used because it must necessarily be the approach adopted in clinical practice. From two subjects $(1 \cdot 3 \%)$ it was found impossible to obtain satisfactory recordings. It was usual for the subject to have watched two or three of his colleagues do the tests before his turn came.

The values for F.E.V.0.5, F.E.V.1.0 and the V.C. were derived from these tracings and F.E.V.0.5\% and F.E.V.1.0\%, with which this paper is primarily concerned, were calculated.

Children Studied. The children studied attended four government schools, two in an industrial area and two in residential suburbs. As the findings were similar in the two areas the results were pooled. A total of 91 males and 79 females between the ages of 5 and 14 years were examined; the numbers at each year of age are set out in Table 1. Care was taken to avoid selection on any obvious grounds, such as intelligence or physical prowess, and volunteers were not called. The study was conducted in conjunction with the periodical examinations conducted by school medical officers. Children with asthma, chronic pulmonary infection, moderate or severe thoracic deformity and very occasional subjects with extremely poor posture and physique were excluded. Approximately $10 \%$ of the children were immigrants; their results were comparable with those of Australian children.

TABLE 1

AGE DISTRIBUTION OF SUBJECTS

\begin{tabular}{cc|c|c}
\hline \multirow{2}{*}{ Year of Life } & \multicolumn{2}{|c}{ Number of Patients } \\
\cline { 2 - 4 } & \multicolumn{1}{c|}{ Female } & Male \\
\hline & 6 & 3 & 3 \\
7 & 7 & 4 \\
8 & 1 & 7 \\
9 & $10-21$ & $7-21$ \\
10 & 7 & 11 \\
11 & 9 & 10 \\
12 & 12 & 25 \\
13 & 14 & $14-70$ \\
14 & $16-58$ & 91 \\
\hline
\end{tabular}

\section{Results}

The correlation coefficients and regression equations relating F.E.V.0.5\% and F.E.V. $1.0 \%$ to age and standing height are set out in Table 2 for both the male and female series. In the latter there is a good correlation between F.E.V.0.5\% and F.E.V. $1.0 \%$ and each of the other parameters; all the correlation coefficients are significant at the $1 \%$ level. In the male series significant correlations are found only in relation to F.E.V.0.5\%, while those for F.E.V.1.0\% are virtually zero. The reason for this lies in the stability of F.E.V.0.5\% and F.E.V.1.0\% over the whole range of age or height in the boys, whereas in the

TABLE 2

CORRELATION COEFFICIENTS AND REGRESSION EQUATIONS FOR F.E.V. $0.5 \%$ AND F.E.V. $1.0 \%$ ON STANDING HEIGHT AND AGE

\begin{tabular}{|c|c|c|c|c|}
\hline Procedure & Sex & $\mathbf{r}$ & Regression Equation & $95 \%$ Tolerance Limits at Mean Values \\
\hline F.E.V. $0.5 \%$ on standing height (S) (in.) & $\mathbf{F}$ & $\begin{array}{l}0 \cdot 577^{* *} \\
0 \cdot 216^{*}\end{array}$ & $\begin{array}{l}\text { F.E.V. } 0.5 \%=115 \cdot 2-0.993 \mathrm{~S} \\
\text { F.E.V. } 0.5 \%=81 \cdot 7-0.403 \mathrm{~S}\end{array}$ & $\begin{array}{l} \pm 16 \cdot 6 \\
\pm 20 \cdot 8\end{array}$ \\
\hline F.E.V. $0.5 \%$ on age (A) (mth.) & $\begin{array}{l}\mathbf{F} \\
\mathbf{M}\end{array}$ & $\begin{array}{l}0 \cdot 547^{* *} \\
0 \cdot 273^{* *}\end{array}$ & $\begin{array}{l}\text { F.E.V. } 0.5 \%=85 \cdot 0-0.193 \mathrm{~A} \\
\text { F.E.V. } 0.5 \%=72 \cdot 7-0.105 \mathrm{~A}\end{array}$ & $\begin{array}{l} \pm 17 \cdot 0 \\
\pm 20 \cdot 5\end{array}$ \\
\hline F.E.V. $1.0 \%$ on standing height (S) (in.) & $\mathbf{F}$ & $\begin{array}{l}0 \cdot 372^{* *} \\
0.063\end{array}$ & $\begin{array}{l}\text { F.E.V. } 1.0 \%=113 \cdot 9-0.561 \mathrm{~S} \\
\text { F.E.V. } 1.0 \%=87 \cdot 1-0.098 \mathrm{~S}\end{array}$ & $\begin{array}{l} \pm 16 \cdot 5 \\
\pm 17 \cdot 8\end{array}$ \\
\hline F.E.V. $1.0 \%$ on age (A) (yr.) & $\mathbf{F}$ & $\begin{array}{l}0 \cdot 336^{* *} \\
0.053\end{array}$ & $\begin{array}{l}\text { F.E.V. } 1.0 \%=96.2-0.104 \mathrm{~A} \\
\text { F.E.V. } 1.0 \%=83.9-0.017 \mathrm{~A}\end{array}$ & $\begin{array}{l} \pm 16 \cdot 8 \\
\pm 17 \cdot 8\end{array}$ \\
\hline
\end{tabular}

Degrees of freedom: females, 77 ; males, $89 ;{ }^{*}$ significant at $5 \%$ level; ** significant at $1 \%$ level.

* Stem height was also measured but subsequent statistical analysis indicated that it offered no advantage over the simpler measurement of standing height in the prediction of any of the ventilatory indices. The results obtained in relation to stem height were similar in all respects to those for standing height. girls there is a pronounced fall in both values. Fig. 1a shows the regression lines for the absolute values of F.E.V.0.5, F.E.V.1.0 and V.C. on standing height for both sexes. The increase in V.C. with increasing 


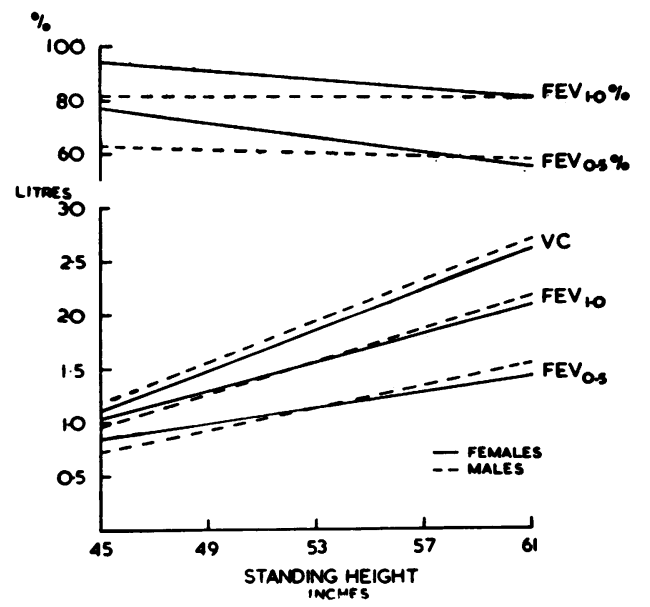

FIG. 1(a)-(lower graph)-Regression lines for absolute values of F.E.V. 0.5 F.E.V. 1.0 and V.C. on standing height for both sexes. Fig. 1 (b).-(upper graph)-Relates values for F.E.V. 0.5\% and F.E.V. 1.0\% (calculated from regression lines in Fig. 1(a)) to standing height for both sexes.

height is similar in girls (continuous lines) and boys (broken lines), but in the boys F.E.V.0.5 and F.E.V.1.0 increase more with increasing height and more in relation to the V.C. than is the case with the girls. This is reflected in the graph (Fig. 1b) relating values for F.E.V.0.5 \% and F.E.V.1.0\%, as calculated from the regression lines in Fig. 1a, with standing height; the calculated values may be compared with the regression lines for the actual values (Figs. 2 and 3). Separate analysis of the results for children of 9 years of age and above and for children less than 9 years old revealed the same pattern of results in all groups as in the two series as a whole. There was therefore no evidence to suggest that lack of

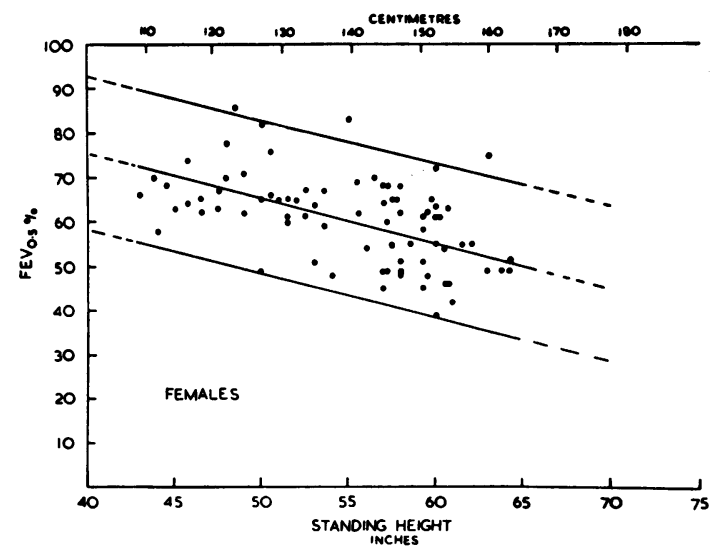

Fig. 2a. cooperation on the part of the older girls or younger boys would serve as an explanation of the relative 'expiratory inefficiency' of those groups. Grouping by age according to the mean values for the ventilatory indices or according to the totals does not affect the findings set out above.

Results of multiple regression analysis showed that little was gained in the prediction of normal values by employing the regression line of F.E.V. $0.5 \%$ or F.E.V.1.0\% on both standing height and age. The influence of age is small relative to that of height and its inclusion does not materially reduce the tolerance limits. It may be added that further analysis of the absolute values of F.E.V.0.5, F.E.V.1.0 and V.C. in relation to standing height and age showed a similarly negligible effect of age.

\section{Discussion}

The results obtained for vital capacity in this survey are almost identical with those of other observers and hence the present paper is confined chiefly to a consideration of the values for the percentage of the vital capacity expired in the first half-second and first second of a forced expiration. In clinical work, prediction of normal values based on age alone is obviously unsatisfactory because it ignores the important factor of size. In the present study, as in others, age (over the range studied) was found to exert little effect on the several indices of ventilatory capacity compared with the effect of size as indicated by standing or stem height. Standing height is a simple and routine measurement in most paediatric clinics and, as stem height was found to offer no significant advantage, it forms an appropriate basis for the prediction of normal values.

In females F.E.V. $0.5 \%$ ranged from $70 \%$ at a

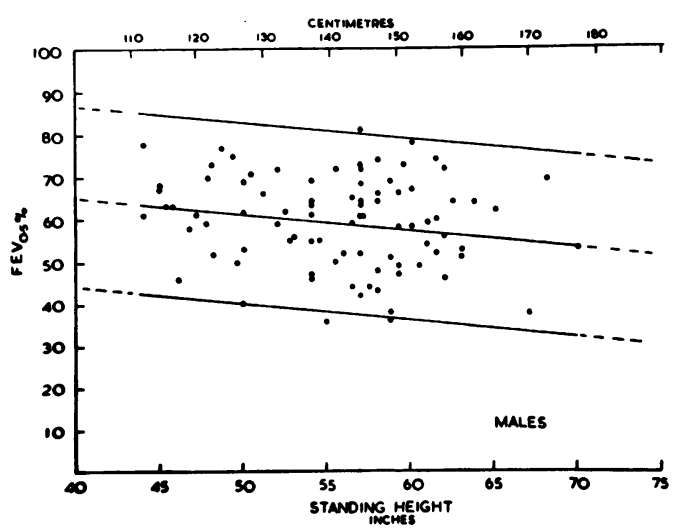

FIG. 2 b.

FIG. 2.-Actual values for F.E.V. $0.5 \%$ plotted against standing height with regression lines and $95 \%$ tolerance limits: $(a)$ females, $(b)$ males. 


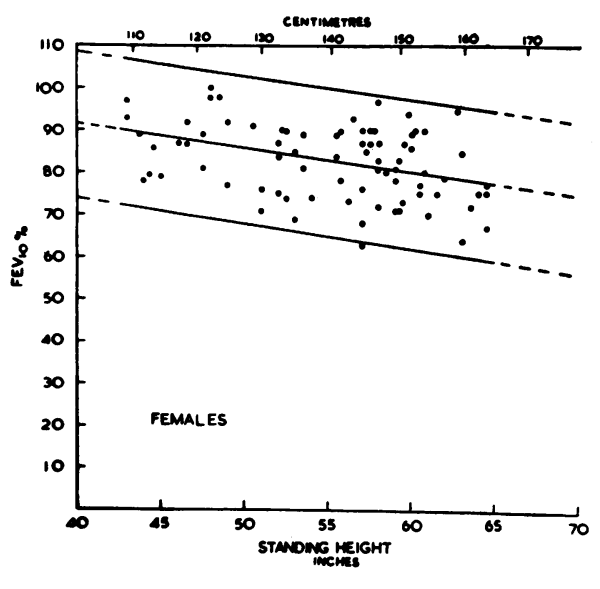

Fig. 3a.

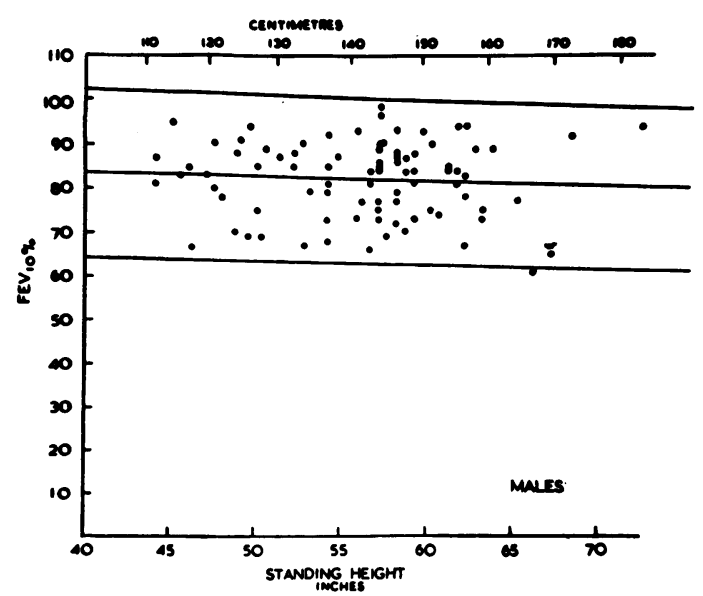

Fig. 3b.

FIG. 3.-Actual values for F.E.V. $1.0 \%$ plotted against standing height with regression lines and $95 \%$ tolerance limits: $(a)$ females, $(b)$ males.

height of $45 \mathrm{in}$. $(114 \mathrm{~cm}$.) to $50 \%$ at $65 \mathrm{in} .(165 \mathrm{~cm}$.) and F.E.V.1.0\% from $88 \%$ to $77 \%$ with $95 \%$ tolerance limits of $\pm 17 \%$ in each case. In the males F.E.V.0.5\% ranged from $63 \%$ at 45 in. $(114 \mathrm{~cm}$.$) to 55 \%$ at 65 in. $(165 \mathrm{~cm}$.) and F.E.V.1.0\% from $82 \%$ to $78 \%$ with $95 \%$ tolerance limits of $\pm 20 \%$. As the increase of vital capacity with increasing height is similar in boys and girls the difference in behaviour is due to different 'rates' of increase in F.E.V.1.0 and F.E.V.0.5 with increasing height; in young boys the absolute values for these indices are lower than for girls (although the V.C. is higher) but over a height of about $4 \mathrm{ft}$. 6 in. the boys have the higher values (although the V.C. increase in boys and girls is the same). No explanation for this sex difference is apparent but it is worth noting (a) that the similarity of the line relating V.C. and height in boys and girls has been reported in other studies, and $(b)$ that at the age of 14 years the present values for F.E.V.0.5\% and F.E.V.1.0\% are those regarded as normal for adults of both sexes. These observations, combined with the finding that the results are similar when the younger and older children are studied as separate groups, suggest that the difference between the sexes is a real one and is not attributable to lack of cooperation on the part of any sub-groups in the performance of the vital capacity or forced expiration manoeuvres.

\section{Summary}

Indices of ventilatory capacity derived from the forced expiratory spirograms of a series of healthy school children are related to standing height.

Attention is drawn to certain differences between the sexes in regard to the proportion of the vital capacity expired in the first second or half-second of a forced expiration.

I am indebted to Dr. B. McCloskey and the School Medical Officers for their cooperation, and to Dr. Howard Williams for his interest in the project.

The statistical analysis was carried out in the Statistics Department of the University of Melbourne, notably by Miss Betty Laby, to whom my thanks are due.

\section{REFERENCES}

Gandevia, B. and Hugh-Jones, P. (1957). Terminology for measurements of ventilatory capacity: A report to the Thoracic Society. Thorax, 12, 290.

Jones, H. E. (1955). The vital capacity of children. Arch. Dis. Childh., 30, 445 .

Turner, J. A. and McLean, R. L. (1951). Spirometric measurements of lung function in healthy children. Pediatrics, 7,360 . 